\title{
Association between polymorphisms in GGPS1 and RANKL genes and postmenopausal osteoporosis in Romanian women
}

CIUBEAN Alina Deniza ${ }^{1}$, IRSAY Laszlo ${ }^{1}$, UNGUR Rodica Ana ${ }^{1}$, CIORTEA Viorela Mihaela ${ }^{1}$, BORDA Ileana Monica ${ }^{1}$, DOGARU Bombonica Gabriela ${ }^{1}$, TRIFA Adrian Pavel ${ }^{2}$, BUZOIANU Anca Dana ${ }^{3}$

Corresponding author: IRSAY Laszlo: irsaylaszlo@gmail.com

\footnotetext{
1. University of Medicine and Pharmacy “Iuliu Hațieganu”, Department of Rehabilitation Medicine, Cluj-Napoca, Romania

${ }^{2}$ University of Medicine and Pharmacy“ "Iuliu Hațieganu”, Department of Genetics, Cluj-Napoca, Romania

${ }^{3}$ University of Medicine and Pharmacy“ Iuliu Haţieganu”, Department of Pharmacology, Toxicology and Clinical Pharmacology, Cluj-Napoca, Romania
}

\begin{abstract}
Objectives: This study aimed to assess the relationship between bone mineral density, fragility fractures, fracture risk and polymorphisms of two osteoporosis-candidate genes (GGPS1 and RANKL) in Romanian women with postmenopausal osteoporosis.

Methods: An analytical, prospective, transversal, observational, case-control study on 364 postmenopausal women, of which 228 were previously diagnosed with osteoporosis, was carried out between June 2016 and August 2017 in Cluj Napoca, Romania. Clinical data and blood samples were collected from all study participants. Polymorphisms in GGPS1 and RANKL genes were genotyped using TaqMan SNP Genotyping assays, run on a QuantStudio 3 real-time PCR machine.
\end{abstract}

Results: The CT genotype in GGPS1 rs 10925503 was associated with significant lower bone mineral density values at lumbar spine and femoral neck sites and a higher fracture risk compared to controls. No significant association was found between genotypes of RANKL rs 2277439 with bone mineral density or fracture risk compared to the healthy controls.

Conclusions: Our study showed a strong association between low bone mineral density and genotype CT of GGPS1 rs 10925503 polymorphisms. No association was found for RANKL rs2277439 polymorphism.

Key words: postmenopausal osteoporosis; genetic polymorphism; candidate genes; bone mineral density; fracture risk,

\section{Introduction}

Osteoporosis (OP) is a common disease characterized by a systemic impairment of bone mass and microarchitecture, that results in fragility fractures. With an aging population, the medical and socio-economic effect of OP, particularly postmenopausal OP, will increase further (1). Because bone loss occurs insidiously and is initially asymptomatic, OP is often only diagnosed after the first clinical fracture has occurred (2).

The measurement of bone mineral density (BMD) by Dual-energy X-ray absorptiometry (DXA) is a valid method to diagnose OP and to predict the risk of fracture (3). The fracture-risk assessment tool $\left(\right.$ FRAX $\left.^{\circledR}\right)$, integrates clinical risk factors with DXAbased BMD to predict an individual's 10-year risk of

sustaining a hip fracture, as well as the 10-year probability of having a major osteoporotic fracture at the election sites of spine, forearm, hip, or shoulder (4).

Among other risk factors, OP has a strong genetic component and it is assumed that $50 \%$ to $80 \%$ of the variability of BMD may be explained by genetic or hereditary factors (5). However, despite the studies published in the past two decades, the identification of the genes involved still remains unclear. In recent years, researchers have turned their focus towards multiple pathways due to their important role in skeletal homeostasis and searched for the genes that could have an impact on OP phenotype. The main pathways studied were as 
follows: estrogen (6-8), vitamin D (9-13), mevalonate (14-19), Wnt (20-22) and OPG/RANK/RANKL (23).

Among the genes studied, the RANKL/RANK/OPG pathway gained much interest as it regulates bone remodeling, playing an important role in the cellular interactions between osteoblasts and osteoclasts. Osteoblasts express RANKL, which is a ligand that interacts with receptor activator of NF-k-B (RANK) in the osteoclasts, leading to their activation, differentiation and fusion. Osteoprotegerin (OPG), which is a decoy receptor for RANKL, protects the skeleton from excessive bone resorption by binding to RANKL and preventing it from associating with RANK. When imbalance between bone formation and resorption occurs, it leads to osteoporosis $(24,25)$.

The discovery of mevalonate pathway's role as the target of the antiresorbtive agents from the amino-bisphosphonates (N-BP) class, used in postmenopausal osteoporosis treatment, revealed other important genes to be considered as candidate genes in OP, like geranylgeranyl pyrophosphate synthase (GGPS1) (17-19).

Regardless of the efforts made by researchers world-wide to associate single nucleotide polymorphisms (SNPs) in several genes with bone mineral density (BMD), the results are still inconclusive, and to date, no gene has been definitely identified as a major gene for osteoporosis (26).

The purpose of the present study is to evaluate the relation between BMD, fragility fractures, fracture risk and genotypes of two SNPs in osteoporosis candidate-genes (GGPS1 rs10925503 and RANKL $r s 2277439$ ) in Romanian women with or without postmenopausal osteoporosis.

\section{Methods}

\section{Study population}

An analytical, prospective, transversal, observational, case-control study on 364 postmenopausal Romanian women was carried out between June 2016 and August 2017. Diagnosis of osteoporosis was made using the World Health Organization T-score criteria (T-score $\leq-2.5$ at any site). The women included in the study were divided into two groups based on their T scores: osteoporosis $(n=228)$ and healthy controls $(n=136)$. All the women included in the study were recruited from the
Clinical Rehabilitation Hospital in Cluj-Napoca, Romania.

The inclusion criteria were as follows: women, at least 45 years old, which had been menopausal for at least 1 year. The exclusion criteria were as follows: history of metabolic bone diseases (e.g. hyperparathyroidism, osteomalacia, Paget disease), malignancy or bone metastasis.

Clinical data was collected by interview and from the medical documents of each patient: age, history of fragility fractures at the election sites (vertebral, hip or wrist), lumbar spine (L1-L4), femoral neck and total hip BMD. These data was also used to calculate the 10-year probability of fracture using the FRAX $^{\circledR}$ algorithm. Furthermore, a $2 \mathrm{ml}$ EDTA vial of peripheral blood was collected from each study participant for genotyping the two selected SNPs.

The study was approved by the Ethics Committee of the University of Medicine and Pharmacy "Iuliu Hațieganu" Cluj-Napoca (approval no. 248/09.06.2016). All participants were informed of the characteristics of the study and all gave signed informed consent regarding the genetic testing and clinical data collection prior to inclusion.

\section{SNP genotyping}

Genomic DNA was obtained from peripheral blood withdrawn on EDTA, using commercially available kits (PureLink Genomic DNA Mini Kit, Invitrogen, Thermo Fisher, USA). We genotyped one SNP in two osteoporosis-candidate genes in all patients and controls (GGPS1 rs10925503 and RANKL rs 2277439), using TaqMan SNP Genotyping assays purchased from Applied Biosystems, according to manufacturer's instructions, and run on a QuantStudio 3 real-time PCR machine (Applied Biosystems, Thermo Fisher, USA).

\section{Statistical analysis}

Statistical analysis was performed using MedCalc Statistical Software version 18.6 (MedCalc Software bvba, Ostend, Belgium; http://www.medcalc.org; 2018). Qualitative data were characterized by frequency and percent. Quantitative data were described by mean and standard deviation or median and $25-75$ percentiles, depending on the normality of distribution at Shapiro-Wilk test. Differences between groups were tested using the chi-square, Mann-Whitney or T test, 
whenever appropriate. A p-value $<0.05$ was considered statistically significant.

\section{Results}

The main characteristics of the women included in the study are shown in Table 1. The median and interquartile range (IQR) values of BMD at the election sites (lumbar spine L1-L4, femoral neck and total hip) and fracture risk score based on FRAX $^{\circledR}$ algorithm are shown in Table 2. The allelic and genotypic models between groups are shown in Table 3. Correlation between genotypes and history of fragility fractures are shown in Table 4.

Genotype frequencies of the GGPS1 rs 10925503 SNP in the study population were distributed as follows: $\mathrm{CC}=284(78.02 \%), \mathrm{CT}=74$ $(20.32 \%)$ and $\mathrm{TT}=6(1.66 \%)$, showing that the $\mathrm{C}$ allele frequency is 0.88 , while the $\mathrm{T}$ allele frequency is 0.12 .

The heterozygous CT in GGPS1 rs 10925503 showed significant lower BMD values in the lumbar spine and femoral neck than the homozygous $\mathrm{CC}$ or TT ( $p=0.022$ and $p=0.006$, respectively), but not in the total hip $(p>0.05)$. Also, the 10-year risk of sustaining a hip fracture or other major osteoporotic fracture was significantly higher in the heterozygous group ( $\mathrm{p}=0.008$ and $\mathrm{p}=0.004$, respectively). When comparing the OP group to the control group, statistical significance was found when analyzing the codominant and recessive model $(p<0.003$ and $\mathrm{p}<0.001$, respectively). No association was found between genotypes and history of fragility fracture (all $\mathrm{p}>0.05$ ).

Genotype frequencies of the RANKL rs2277439 SNP in the study population were distributed as follows: $\mathrm{AA}=127$ (34.89\%), $\mathrm{AG}=229$ $(62.91 \%)$ and $\mathrm{GG}=8(2.2 \%)$, showing that the $\mathrm{A}$ allele frequency is 0.67 , while the $\mathrm{G}$ allele frequency is 0.33 .

No statistical significance was found in any of the correlations made for RANKL rs2277439 (all $\mathrm{p}>0.05$ ).

\section{Discussion}

OP is considered as one of the major epidemics of the $21 \mathrm{st}$ century, affecting approximately 200 million people globally, with significant impact on morbidity and mortality and massive socioeconomic burden. It is mainly characterized by decreased BMD and increased risk of bone fragility, and is typically asymptomatic until a fragility fracture occurs (27). Complex diseases such as OP result from the combined effects of variation in a number of genes as well as environmental factors (28). Identification of susceptibility genes underlying complex diseases remains an interesting challenge in the genome era. Previous efforts to identify OP genes have focused on three approaches: genome-wide scans, candidate gene study, and animal models (29).

The genetics of osteoporosis has revealed promising associations between many polymorphisms in candidate genes and bone traits, but mostly lacks sufficient statistical power and show false-positive results. Genes involved in bone formation/resorption pathways have been correlated to the risk of developing OP, and high risk of hip and vertebral fractures, and to BMD values. Therefore, these gene variants could affect homeostasis and bone structure, and as a result, BMD values (26).

Even though in the last two decades researchers have continuously searched for the role of genetic factors in the pathogenesis of bone loss, up to date, there is no conclusive etiologic information about OP or osteoporotic-related fractures. Researchers turned their focus towards genes belonging to pathways that are thought to be involved in bone homeostasis. But up to date, no conclusive data is available, as each author recommends multiplying the results in larger cohorts and other ethnic populations. "Risk alleles" for some of these genes have been observed in some populations, but the SNPs are generally associated with modest effects on the phenotypes of interest (27).

GGPS1 is part of the mevalonate pathway, and it is known to be an important target of aminobisphosphonates (N-BPs) in osteoclasts. It belongs to the trans-prenyltransferase family and is speculated to affect the skeletal response to alendronate (30). However, little is known about its role in the etiology of OP. In postmenopausal Korean women, those with two deletions in the allele of GGPS1 rs3840452 had significantly higher femoral neck BMD and a higher risk of non-response to $\mathrm{N}$ BP therapy (17). In the present research, the heterozygous CT of $r s 10925503$ SNP showed significantly lower BMD values at all measured sites and a higher fracture risk than the homozygous $\mathrm{CC}$ or TT. Also, results show that the TT genotype, and/or the presence of the $\mathrm{T}$ allele could predict an osteoporosis phenotype. Also, it is important to 
mention that the genotypic and allelic frequency was different than previously reported in the Chinese population, where the major allele was found to be T (19).

The RANK/RANKL/OPG system regulates bone remodeling, by playing an important role in the cellular interactions between osteoblasts and osteoclasts (24). This pathway is known to be important to bone physiology, and has led to the design of a drug that reduces the risk of osteoporoticrelated fractures (denosumab) (31). A large collaborative meta-analysis assessing the effects of common genetic variants in SNPs described as associated with osteoporosis and BMD confirmed that variants in the RANK, RANKL or OPG genes influence BMD and/or fracture risk (32). We found no significance in any of the correlations made between genotypes of $r s 2277439$ polymorphism and BMD or fracture risk in our cohort.

This study has several limitations. First, the sample size was modest, as it is a known fact that genetic testing needs higher number of subjects to achieve sufficient statistical power. Secondly, it included only women from one ethnic group and it is not clear if the results can be related to other populations.

To our knowledge, this is the first study to detect an association between SNPs of GGPS1 and RANKL genes with BMD and fracture risk in a Romanian cohort of women with postmenopausal osteoporosis. Also, none of the SNPs included in this study has been evaluated before in a Romanian population. Data obtained from the current study could be of importance to Romanian postmenopausal women, as the burden, of OP and osteoporosisrelated fractures, is increasing in Romania, as in other European countries (1).

The success in finding OP genes rests on the collection of data from large cohorts of clinically well-characterized individuals. It is expected that with such statistically robust large-scale studies, many of the genes influenced by OP phenotype will likely be identified in the future.

\section{Conclusions}

Our study showed a strong association between osteoporosis and the heterozygous CT genotype of GGPS1 rs10925503 polymorphism, which showed lower BMD values and a higher fracture risk than the homozygous TT or CT, in the codominant and recessive models. No statistical significance was found between any genotype of RANKL rs2277439 and BMD or fracture risk in Romanian women with postmenopausal osteoporosis.

\section{Conflicts of interests}

There are no conflicts of interests.

\section{References}

1. Rachner TD, Khosla S, Hofbauer LC. Osteoporosis: now and the future. The Lance. 2011; 377(9773):1276-1287.

2. Vestergaard P, Rejnmark L, Mosekilde L. Osteoporosis is markedly underdiagnosed: a nationwide study from Denmark. Osteoporos Int. 2005; 16:134-141.

3. Cummings SR, Bates D, Black DM. Clinical use of bone densitometry: scientific review. JAMA. 2002; 288:1889-1897.

4. Unnanuntana A, Gladnick BP, Donnelly E, et al. The assessment of fracture risk. J Bone Joint Surg Am. 2010; 92:743-753.

5. Ralston SH. Osteoporosis as an hereditary disease. Clinical reviews in bone and mineral metabolism. $2010 ; 8(2): 68-76$.

6. Gennari L, Merlotti D, De Paola V, et al. Estrogen receptor gene polymorphisms and the genetics of osteoporosis: a HuGE review. Am J Epidemiol. 2005; 161:307-320.

7. Ioannidis JP, Ralston SH, Bennett ST, et al. Differential genetic effects of ESR1 gene polymorphisms on osteoporosis outcomes. JAMA. 2004; 292:2105-14.

8. Ioannidis JP, Stavrou I, Trikalinos TA, et al. Association of polymorphisms of the estrogen receptor alpha gene with bone mineral density and fracture risk in women: a meta-analysis. J Bone Miner Res. 2002; 17:2048-2060.

9. Li Y, Xi B, Li K, et al. Association between vitamin $\mathrm{D}$ receptor gene polymorphisms and bone mineral density in Chinese women. Mol Biol Rep. 2012; 39:5709-5717.

10. Fang Y, van Meurs JB, d'Alesio A, et al. Promoter and 3'-untranslated-region haplotypes in the vitamin $\mathrm{d}$ receptor gene predispose to osteoporotic fracture: the Rotterdam study. Am J Hum Genet .2005; 77:807-823.

11. Kurt O, Yilmaz-Aydogan $\mathrm{H}$, Uyar $\mathrm{M}$, et al. Evaluation of ERalpha and VDR gene polymorphisms in relation to bone mineral density in Turkish postmenopausal women. Mol Biol Rep. 2012; 39:6723-3730. 
12. Jakubowska-Pietkiewicz E, Mlynarski W, Klich I, et al. Vitamin D receptor gene variability as a factor influencing bone mineral density in pediatric patients. Mol Biol Rep. 2012; 39:62436250.

13. Horst-Sikorska W, Dytfeld J, Wawrzyniak A, et al. Vitamin D receptor gene polymorphisms, bone mineral density and fractures in postmenopausal women with osteoporosis. Mol Biol Rep. 2013; 40:383-390.

14. Levy ME, Parker RA, Ferrell RE, et al. Farnesyl diphosphate synthase: a novel genotype association with bone mineral density in elderly women. Maturitas .2007; 57(3):247-252.

15. Marini F, Falchetti A, Silvestri S, et al. Modulatory effect of farnesyl pyrophosphate synthase (FDPS) rs2297480 polymorphism on the response to long-term amino-bisphosphonate treatment in postmenopausal osteoporosis. Current Medical research and opinion .2008; 24(9):2609-2615.

16. Olmos JM, Zarrabeitia MT, Hernandez JL, et al. Common allelic variants of the farnesyl diphosphate synthase gene influence the response of osteoporotic women to bisphosphonates. The pharmacogenomics journal .2012; 12(3):227.

17. Choi HJ, Choi JY, Cho SW, et al. Genetic polymorphism of geranylgeranyl diphosphate synthase (GGSP1) predicts bone density response to bisphosphonate therapy in Korean women. Yonsei medical journal. 2010; 51(2):231-238.

18. Wang $\mathrm{C}$, Zheng $\mathrm{H}$, He JW, et al. Genetic polymorphisms in the mevalonate pathway affect the therapeutic response to alendronate treatment in postmenopausal Chinese women with low bone mineral density. The pharmacogenomics journal .2015; 15(2): 158 .

19. Han LW, Ma DD, Xu XJ, et al. Association Between Geranylgeranyl Pyrophosphate Synthase Gene Polymorphisms and Bone Phenotypes and Response to Alendronate Treatment in Chinese Osteoporotic Women. Chinese Medical Sciences Journal .2016; 31(1):8-16.

20. Koay MA, Woon PY, Zhang Y, et al. Influence of LRP5 polymorphisms on normal variation in BMD. Journal of Bone and Mineral Research .2004;19(10):1619-1627.

21. Bollerslev J, Wilson SG, Dick IM, et al. LRP5 gene polymorphisms predict bone mass and incident fractures in elderly Australian women. Bone. 2005; 36(4):599-606.
22. Hartikka H, Mäkitie $O$, Männikkö $M$, et al. Heterozygous mutations in the LDL receptor-related protein 5 (LRP5) gene are associated with primary osteoporosis in children. Journal of bone and mineral research .2005; 20(5):783-789.

23. Riancho JA, Hernández JL. Pharmacogenomics of osteoporosis: a pathway approach. Pharmacogenomics .2012; 13(7):815-829.

24. Boyce BF, Xing L. Biology of RANK, RANKL, and osteoprotegerin. Arthritis research \& therapy .2007; 9(1):S1.

25. Tu P, Duan P, Zhang RS, et al. Polymorphisms in genes in the RANKL/RANK/OPG pathway are associated with bone mineral density at different skeletal sites in post-menopausal women. Osteoporosis International .2015; 26(1):179-185.

26. Venegas KR, Gómez MA, Garre MC, et al. Pharmacogenetics of osteoporosis: towards novel theranostics for personalized medicine? Omics: a journal of integrative biology. 2012; 16(12):638651.

27. S.H. Ralston, A.G. Uitterlinden, Genetics of osteoporosis, Endocr. Rev. 31 (2010) 629-662.

28. Fodor D, Vesa S, Albu A, Simon S, Craciun A, Muntean L. The relationship between the metabolic syndrome and its components and bone status in postmenopausal women. Acta Physiol Hung. 2014;101(2):216-27.

29. Al Anouti F, Taha Z, Shamim S, Khalaf K, Al Kaabi L, Alsafar H. An insight into the paradigms of osteoporosis: From genetics to biomechanics. Bone Reports. 2019 Jul 17:100216.

30. Dudakovic A, Wiemer AJ, Lamb KM, Vonnahme LA, Dietz SE, Hohl RJ. Inhibition of geranylgeranyl diphosphate synthase induces apoptosis through multiple mechanisms and displays synergy with inhibition of other isoprenoid biosynthetic enzymes. Journal of Pharmacology and Experimental Therapeutics. 2008 Mar 1;324(3):1028-36.

31. Cummings, Steven R., et al. "Vertebral fractures after discontinuation of denosumab: a post hoc analysis of the randomized placebo-controlled FREEDOM trial and its extension." Journal of Bone and Mineral Research 33.2 (2018): 190-198.

32. Richards, J. Brent, et al. "Collaborative metaanalysis: associations of 150 candidate genes with osteoporosis and osteoporotic fracture." Annals of internal medicine 151.8 (2009): 528-537. 
Table 1. Clinical characteristics of women included in the study

\begin{tabular}{|c|c|c|c|}
\hline Variables & $\begin{array}{c}\text { Osteoporosis } \\
n=228\end{array}$ & $\begin{array}{c}\text { Controls } \\
n=136\end{array}$ & $p$-value \\
\hline Age, mean \pm SD [years] & $65.5 \pm 7.39$ & $63.45 \pm 8.16$ & 0.014 \\
\hline BMI, mean $\pm \mathrm{SD}\left[\mathrm{kg} / \mathrm{m}^{2}\right]$ & $27.05 \pm 4.74$ & $30.56 \pm 5.40$ & $<0.001$ \\
\hline Age at menopause, mean \pm SD [years] & $47.26 \pm 4.84$ & $48.35 \pm 4.88$ & 0.045 \\
\hline Time of amenorrhea, mean \pm SD [years] & $18.25 \pm 8.36$ & $15.08 \pm 8.82$ & 0.001 \\
\hline Previous fragility fracture (vertebral, hip, wrist, humerus), $n(\%)$ & $132(57.9)$ & $0(0)$ & - \\
\hline Current smoking, $n(\%)$ & $10(4.4)$ & $6(4.4)$ & 0.991 \\
\hline Alcohol consumption $>3$ units/day, $n(\%)$ & $3(1.3)$ & $0(0)$ & - \\
\hline Parent fractured hip, $n(\%)$ & $13(5.6)$ & $8(5.8)$ & 0.943 \\
\hline Lumbar spine (L1-L4) BMD, mean $\pm \mathrm{SD}\left[\mathrm{g} / \mathrm{cm}^{2}\right]$ & $0.851 \pm 0.11$ & $1.116 \pm 0.15$ & $<0.001$ \\
\hline Femoral neck BMD, mean \pm SD $\left[\mathrm{g} / \mathrm{cm}^{2}\right]$ & $0.751 \pm 0.10$ & $0.969 \pm 0.21$ & $<0.001$ \\
\hline Total hip BMD, mean $\pm \mathrm{SD}\left[\mathrm{g} / \mathrm{cm}^{2}\right]$ & $0.791 \pm 0.5$ & $0.968 \pm 0.21$ & $<0.001$ \\
\hline FRAX - 10 year risk of major osteoporotic fracture, mean \pm SD [\%] & $8.04 \pm 4.68$ & $4.34 \pm 2.47$ & $\mathbf{0 . 0 0 5}$ \\
\hline FRAX - 10 year risk of hip fracture, mean \pm SD [\%] & $2.76 \pm 2.97$ & $0.82 \pm 1.47$ & $<0.001$ \\
\hline
\end{tabular}

Table 2. Bone mineral density values and fracture risk score among genotypes

\begin{tabular}{|c|c|c|c|c|c|c|}
\hline Gene (SNP) & Genotype & $\begin{array}{l}\text { BMD L1-L4 } \\
\text { g/cm² (IQR) }\end{array}$ & $\begin{array}{c}\text { BMD } \\
\text { FEMORAL } \\
\text { NECK g/cm² } \\
(\text { IQR) }\end{array}$ & $\begin{array}{c}\text { BMD TOTAL } \\
\text { HIP g/cm² (IQR) }\end{array}$ & $\begin{array}{c}\text { MAJOR } \\
\text { OSTEOPOROTIC } \\
\text { FRACTURE RISK } \\
\left.\text { (FRAX }^{\mathbb{}}\right) \\
\end{array}$ & $\begin{array}{c}\text { HIP } \\
\text { FRACTURE } \\
\text { RISK } \\
\text { (FRAX }^{\circledR} \text { ) } \\
\end{array}$ \\
\hline \multirow{4}{*}{$\begin{array}{c}\text { GGPS1 } \\
\text { rs10925503 }\end{array}$} & $\mathrm{CC}$ & $\begin{array}{c}0.934(0.829 ; \\
1.069)\end{array}$ & $\begin{array}{c}0.801(0.713 \\
0.886)\end{array}$ & $\begin{array}{c}0.851(0.761 ; \\
0.971)\end{array}$ & $5.4(3.6 ; 8.07)$ & $1.2(0.5 ; 2.4)$ \\
\hline & CT & $\begin{array}{c}0.878(0.763 ; \\
1.047)\end{array}$ & $\begin{array}{c}0.747(0.697 \\
0.842)\end{array}$ & $\begin{array}{c}0.809(0.735 \\
0.898)\end{array}$ & $6.2(4.4 ; 10.2)$ & $1.6(0.8 ; 4)$ \\
\hline & TT & $\begin{array}{c}1.041(1.008 ; \\
1.190)\end{array}$ & $\begin{array}{c}0.909(0.838 \\
0.967)\end{array}$ & $\begin{array}{l}0.955(0.395 ; \\
\quad 1.019)\end{array}$ & $3.1(3 ; 4.5)$ & $0.3(0.2 ; 0.7)$ \\
\hline & $\mathrm{CT}+\mathrm{TT}$ & $\begin{array}{c}0.894(0.770 \\
1.050)\end{array}$ & $\begin{array}{c}0.756(0.703 \\
0.850)\end{array}$ & $\begin{array}{l}0.814(0.737 ; \\
0.925)\end{array}$ & $5.9(4.2 ; 9.9)$ & $1.4(0.8 ; 3.4)$ \\
\hline \multirow[b]{2}{*}{$\mathrm{p}$-value } & $\begin{array}{l}\text { CC vs CT } \\
\text { vs TT }\end{array}$ & 0.022 & 0.006 & 0.077 & 0.008 & 0.004 \\
\hline & $\begin{array}{l}\mathrm{CC} \text { vs } \\
\mathrm{CT}+\mathrm{TT}\end{array}$ & 0.254 & 0.092 & 0.079 & 0.095 & 0.089 \\
\hline \multirow{4}{*}{$\begin{array}{l}\text { RANKL } \\
\text { rs } 2277439\end{array}$} & AA & $\begin{array}{c}0.944(0.822 ; \\
1.057)\end{array}$ & $\begin{array}{l}0.799(0.722 \\
0.891)\end{array}$ & $\begin{array}{c}0.944(0.822 \\
1.054)\end{array}$ & $5.7(3.6 ; 8.2)$ & $1.3(0.5 ; 2.6)$ \\
\hline & AG & $\begin{array}{c}0.924(0.825 ; \\
1.075)\end{array}$ & $\begin{array}{l}0.784(0.705 \\
0.871) \\
\end{array}$ & $\begin{array}{c}0.924(0.826 ; \\
1.074)\end{array}$ & $5.7(3.6 ; 8.3)$ & $1.3(0.5 ; 2.4)$ \\
\hline & GG & $\begin{array}{c}0.999(0.845 ; \\
1.385)\end{array}$ & $\begin{array}{c}0.839(0.687 \\
0.912)\end{array}$ & $\begin{array}{c}0.999(0.885 ; \\
\quad 1.306)\end{array}$ & $4.5(3 ; 7.7)$ & $0.9(0.3 ; 1.6)$ \\
\hline & $\mathrm{AG}+\mathrm{GG}$ & $\begin{array}{c}0.924(0.825 ; \\
1.077)\end{array}$ & $\begin{array}{c}0.799(0.722 \\
0.891)\end{array}$ & $\begin{array}{l}0.842(0.758 ; \\
0.984)\end{array}$ & $5.7(3.6 ; 8.3)$ & $1.3(0.5 ; 2.4)$ \\
\hline \multirow[b]{2}{*}{$\mathrm{p}$-value } & $\begin{array}{l}\text { AA vs AG } \\
\text { vs GG }\end{array}$ & 0.386 & 0.648 & 0.559 & 0.658 & 0.670 \\
\hline & $\begin{array}{l}\mathrm{AA} \text { vs } \\
\mathrm{AG}+\mathrm{GG}\end{array}$ & 0.944 & 0.466 & 0.500 & 0.615 & 0.908 \\
\hline
\end{tabular}

$\mathrm{BMD}=$ bone mineral density; $\mathrm{IQR}=$ interquartile range; FRAX ${ }^{\circledR}=$ Fracture Risk Assesment Tool 
Table 3. Allelic and genotypic distribution between osteoporotic women and controls

\begin{tabular}{|c|c|c|c|c|c|c|}
\hline Gene & Polymorphism & Model/alleles & $\begin{array}{l}\text { Genotypes, } \\
\text { alleles }\end{array}$ & $\begin{array}{c}\text { Osteoporosis } \\
(\%) \\
(n=228)\end{array}$ & $\begin{array}{c}\text { Controls } \\
(\%) \\
n=136\end{array}$ & p-value \\
\hline \multirow{9}{*}{ GGPS1 } & \multirow{9}{*}{ rs10925503 } & \multirow{3}{*}{ Codominant } & $\mathrm{CC}$ & $177(77.6)$ & $107(78.7)$ & \multirow{3}{*}{0.003} \\
\hline & & & $\mathrm{CT}$ & $50(22)$ & $24(17.7)$ & \\
\hline & & & $\mathrm{TT}$ & $1(0.4)$ & $5(3.6)$ & \\
\hline & & \multirow{2}{*}{ Recessive } & $\mathrm{CT}+\mathrm{CC}$ & $227(99.6)$ & $131(95.6)$ & \multirow{2}{*}{0.001} \\
\hline & & & TT & $1(0.4)$ & $5(4.4)$ & \\
\hline & & \multirow{2}{*}{ Dominant } & $\mathrm{CT}+\mathrm{TT}$ & $51(22.4)$ & $29(21.3)$ & \multirow{2}{*}{0.816} \\
\hline & & & $\mathrm{CC}$ & $177(77.6)$ & $107(78.7)$ & \\
\hline & & Major allele & $\mathrm{C}$ & $404(88)$ & $238(87.5)$ & 0.851 \\
\hline & & Minor allele & $\mathrm{T}$ & $52(12)$ & $34(12.5)$ & 0.945 \\
\hline \multirow{9}{*}{ RANKL } & \multirow{9}{*}{ rs2277439 } & \multirow{3}{*}{ Codominant } & $\mathrm{AA}$ & $74(32.5)$ & $53(39)$ & \multirow{3}{*}{0.378} \\
\hline & & & $\mathrm{AG}$ & $148(64.9)$ & $81(59.6)$ & \\
\hline & & & GG & $6(2.6)$ & $2(1.5)$ & \\
\hline & & \multirow{2}{*}{ Recessive } & $\mathrm{AG}+\mathrm{AA}$ & $222(97.4)$ & $134(98.5)$ & \multirow{2}{*}{0.465} \\
\hline & & & GG & $6(2.6)$ & $2(1.5)$ & \\
\hline & & \multirow{2}{*}{ Dominant } & $\mathrm{AG}+\mathrm{GG}$ & $154(67.5)$ & $83(61)$ & \multirow{2}{*}{0.207} \\
\hline & & & $\mathrm{AA}$ & $74(32.5)$ & $53(39)$ & \\
\hline & & Major allele & A & $296(65)$ & $187(68)$ & 0.497 \\
\hline & & Minor allele & $\mathrm{G}$ & $160(35)$ & $85(32)$ & 0.637 \\
\hline
\end{tabular}

Table 4. Correlations between genotypes and history of fragility fractures in the study population $(\mathbf{n}=364)$

\begin{tabular}{|c|c|c|c|c|c|c|c|}
\hline SNP & Genotypes & $\begin{array}{c}\text { History } \\
\text { of } \\
\text { fracture } \\
\text { n }(\%)\end{array}$ & $\begin{array}{c}\text { No history of } \\
\text { fracture } \\
\text { n (\%) }\end{array}$ & $\begin{array}{l}\text { Vertebral } \\
\text { fractures }\end{array}$ & $\begin{array}{l}\text { No } \\
\text { vertebral } \\
\text { fractures }\end{array}$ & $\begin{array}{l}\text { Peripheral } \\
\text { fractures }\end{array}$ & $\begin{array}{c}\text { No } \\
\text { peripheral } \\
\text { fractures }\end{array}$ \\
\hline \multirow{4}{*}{$\begin{array}{c}\text { GGPS1 } \\
r s 10925503\end{array}$} & $\mathrm{CC}$ & $\begin{array}{c}100 \\
(35.2)\end{array}$ & $184(64.8)$ & $72(25.4)$ & $212(74.6)$ & $45(15.8)$ & $239(84.2)$ \\
\hline & CT & $32(43.2)$ & $42(56.8)$ & $22(29.7)$ & $52(70.3)$ & $17(23)$ & $57(77)$ \\
\hline & TT & $0(0.0)$ & $6(100)$ & $0(0.0)$ & $6(100)$ & $0(0.0)$ & $6(100)$ \\
\hline & p-value & \multicolumn{2}{|c|}{0.078} & \multicolumn{2}{|c|}{0.258} & \multicolumn{2}{|c|}{0.186} \\
\hline \multirow{4}{*}{$\begin{array}{l}\text { RANKL } \\
r s 2277439\end{array}$} & AA & $41(32.3)$ & $86(67.7)$ & $28(22)$ & $99(78)$ & $19(15)$ & $108(85)$ \\
\hline & $\mathrm{AG}$ & $89(38.9)$ & $140(61.1)$ & $66(28.8)$ & $163(71.2)$ & $41(17.9)$ & $188(82.1)$ \\
\hline & GG & $2(25)$ & $6(75)$ & $0(0.0)$ & $8(100)$ & $2(25)$ & $6(75)$ \\
\hline & p-value & \multicolumn{2}{|c|}{0.372} & \multicolumn{2}{|c|}{0.091} & \multicolumn{2}{|c|}{$\frac{1}{0.648}$} \\
\hline
\end{tabular}

